\title{
BMJ Open Lifetime socioeconomic circumstances and chronic pain in later adulthood: findings from a British birth cohort study
}

\author{
Matthew A Jay, ${ }^{\ominus 1,2}$ Rebecca Bendayan, ${ }^{\circledR 3,4}$ Rachel Cooper, ${ }^{4}$ Stella G Muthuri ${ }^{4}$
}

To cite: Jay MA, Bendayan R, Cooper R, et al. Lifetime socioeconomic circumstances and chronic pain in later adulthood: findings from a British birth cohort study. BMJ Open 2019;9:e024250. doi:10.1136/ bmjopen-2018-024250

- Prepublication history and additional material for this paper are available online. To view these files, please visit the journal online (http://dx.doi. org/10.1136/bmjopen-2018024250).

Received 17 May 2018 Revised 2 October 2018 Accepted 17 December 2018

Check for updates

(c) Author(s) (or their employer(s)) 2019. Re-use permitted under CC BY. Published by BMJ.

${ }^{1}$ GOS Institute of Child Health, University College London,

London, UK

${ }^{2}$ Department of Anaesthesia and Pain Medicine, Great Ormond Street Hospital For Children NHS Foundation Trust, London, UK ${ }^{3}$ Department of Biostatistics and Health Informatics, King's College London, Institute of Psychiatry, Psychology and Neuroscience, London, UK ${ }^{4}$ MRC Unit for Lifelong Health and Ageing, University College London, London, UK

Correspondence to Mr Matthew A Jay; matthew.jay.15@ucl.ac.uk

\section{ABSTRACT}

Objectives To investigate associations between a range of different indicators of socioeconomic position (SEP: occupational class, education, household overcrowding and tenure, and experience of financial hardship) across life and chronic widespread and regional pain (CWP and CRP) at age 68.

Design Prospective birth cohort; the Medical Research Council National Survey of Health and Development. Setting England, Scotland and Wales.

Participants Up to 2378 men and women who have been followed-up since birth in 1946 to age 68.

Primary outcome measures $0 n$ the basis of their selfreport of pain at age 68, participants were classified as: CWP (American College of Rheumatology criteria), CRP (pain of at least 3 months' duration but that does not meet the definition of CWP), other pain ( $<3$ months in duration) or no pain.

Results At age 68, the prevalence of CWP was $13.3 \%$ and $7.8 \%$ in women and men, respectively, and that of CRP was $32.3 \%$ and $28.7 \%$ in women and men, respectively. There was no clear evidence that indicators of SEP in childhood or later adulthood were associated with pain. Having experienced (vs not) financial hardship and being a tenant (vs owner-occupier) in earlier adulthood were both associated with an increased risk of CWP; for example, moderate hardship adjusted relative risk ratio $\left(\mathrm{RRR}_{\mathrm{ad}}\right) 2.32$ (95\% Cl: 1.19 to 4.52) and most hardship RRR $_{\text {adj }} 4.44$ (95\% $\mathrm{Cl}: 2.02$ to 9.77$)$. Accumulation of financial hardship across earlier and later adulthood was also associated with an increased risk of CWP.

Conclusions Consideration of socioeconomic factors in earlier adulthood may be important when identifying targets for intervention to prevent CWP in later life.

\section{INTRODUCTION}

Chronic widespread and regional pain (CWP and CRP) are leading causes of disability globally, ${ }^{1}$ particularly in later adulthood. ${ }^{2}$ CWP is defined according to the American College of Rheumatology (ACR) criteria $^{3}$ as pain present for 3 months or longer, both above and below the waist; on both the left and right side of the body and in the axial skeleton. CRP is any pain present for 3 months

\section{Strengths and limitations of this study}

- We used data from a sample of older adults in Great Britain who were representative of the general population born at a similar time.

- Studying a wide range of indicators of SEP over a 60-year-period provided a unique insight into the associations between SEP and CWP and CRP at age 68.

- Prospective data collection across life reduced the risk of misclassification bias.

- The study might have been subject to survivor bias with the result that associations may be biased towards the null.

or longer that does not otherwise meet these ACR criteria. In a systematic review, the prevalence of chronic pain among adults in the UK was estimated to be $44 \%$ (95\% CI: $38 \%$ to $49 \%$ ) and that of CWP to be $14 \%$ (95\% CI: $12 \%$ to $16 \%),{ }^{4}$ an estimate that is similar in other countries. ${ }^{56}$ Understanding risk factors for CWP and CRP, such as socioeconomic position (SEP) on which there is currently limited population-level evidence, ${ }^{7}$ is, therefore, important to develop preventive public health strategies. Pain is a biopsychosocial phenomenon, meaning that it is known to be affected by a range of biological, psychological and social factors. ${ }^{8}$ SEP is, therefore, an important target for study and potential intervention.

Few studies have examined associations between SEP and CWP, CRP or a combined measure of chronic pain; they have largely been cross-sectional, tending to treat SEP as a confounder. ${ }^{9-14}$ They mostly examine only one or two indicators of SEP despite its multifaceted nature ${ }^{15-17}$ with different aspects of SEP potentially related to CWP and CRP in different ways. Few also consider the role of SEP across life. ${ }^{18-20}$ Of those that do, Macfarlane $e t a l^{18}$ and Power et $a l^{19}$ using the 1958 
British birth cohort, found associations between lower SEP (paternal and own occupational class during childhood and earlier adulthood, respectively) and higher risk of CWP at age 44-45. Macfarlane et $a l^{18}$ also found that lower occupational class was associated with an increased risk of CRP at specific sites; many of these associations, however, were attenuated after adjustment. Goosby, ${ }^{20}$ using the US Health and Retirement Study, found that higher education and income were associated with lower risk of chronic pain (ie, arthritis/rheumatism; back or neck problems or received treatment in the past 12 months; frequent or severe headaches and any other chronic pain) in people aged 18-64. The extent to which SEP across life is associated with CWP or CRP in participants beyond midlife remains to be determined. Taking a life-course approach, by investigating SEP at different life stages, could help to identify new opportunities for intervention as the accumulation of exposure to social stressors across life may be associated with an increased risk of CWP and CRP at older ages. ${ }^{21}$

There are important gaps in knowledge. First, the multifaceted nature of SEP has been neglected in research into the association between SEP and CWP and CRP. Our first aim was, therefore, to investigate whether a range of different SEP indicators across childhood and adulthood were associated with CWP, CRP or other pain at age 68. Examining CWP and CRP is important as they may have different underlying aetiologies. Second, associations between SEP and CWP or CRP in later adulthood cannot be fully understood without considering how SEP operates across life. We, therefore, also aimed to test whether observed associations are cumulative. We hypothesised that (1) lower levels of each SEP indicator would be associated with an increased risk of CWP (but not necessarily CRP on the basis of the weaker associations previously observed $^{18}$ ) in later adulthood and (2) accumulation of low SEP across life would also be associated with increased risk of CWP.

\section{METHODS}

\section{Sample}

Data were drawn from the Medical Research Council (MRC) National Survey of Health and Development (NSHD), a nationally representative ${ }^{22} 23$ longitudinal study of a sample $(n=5362)$ of single births during the first week of March 1946 in Great Britain. ${ }^{24}$ Data collection occurred approximately every 2 years during childhood and every 5-10 years during adulthood, with 24 data collection rounds up to 2014-2015. ${ }^{22} 2425$ Details on overall participation rates, which were generally high, are available elsewhere. ${ }^{22}{ }^{26}$ Of the 2942 people in the targeted sample for the most recent data collection at age 68, in 2014-2015, 2453 (83.4\%) completed a postal questionnaire. No attempt was made to contact the remaining 2420 study members: 957 (17.8\%) had already died, 620 $(11.6 \%)$ had previously withdrawn from the study, 448 $(8.3 \%)$ had emigrated and were no longer in contact with the study and 395 (7.4\%) had been untraceable for more than 5 years. Participants who responded were eligible for the present study if they had provided responses to questions on pain $(\mathrm{n}=2378)$.

\section{Patient and public involvement statement}

Participants have a lifelong association with NSHD. Over the 70 years of the study, the research team has increasingly involved participants, in line with changing norms about conducting cohort studies, starting at age 16 (in 1962) with the annual dissemination of study findings in birthday cards. Participants receive personal letters whenever they raise queries or provide additional comments, including suggestions for new topics to study. In the last 10 years, the research team has increased the level of participant involvement through invitations to study events (65th and 70th birthday celebrations), public engagement activities and focus groups to discuss clinical sub-studies. When piloting new questionnaires and assessments, we recruit patients from general practices or the University College London Hospital patient public involvement group and take into account their feedback when designing the main-stage fieldwork.

\section{Ascertainment of pain at age 68}

Participants were asked, 'In the last month, have you had any ache or pain which has lasted for oneday or longer? (Please do not include pain occurring only during the course of a feverish illness, such as flu $[s i c])^{\prime}$ (emphasis in original). Those who answered yes were then asked whether they had been aware of this pain for at least 3 months and asked to shade on a four-view body manikin all the areas where they felt pain. Responses to these questions were used to classify participants as having CWP (defined according to the ACR criteria ${ }^{3}$ ). Those who reported pain of at least 3 months' duration but did not meet the CWP definition were classified as CRP and those reporting pain of less than 3 months duration were categorised as having other pain. ${ }^{27}$

\section{Indicators of SEP}

A range of SEP indicators were selected for study a priori in order to capture different facets of the SEP construct including psychosocial as well as material aspects. ${ }^{16} 17$ These indicators were assessed prospectively across life and for the purposes of these analyses were grouped into three life stages (childhood [age 0 to 15]; earlier adulthood [age 26 to 53] and later adulthood [age 60 to 64]). Indicators of childhood SEP were father's occupational class, paternal and maternal education, household overcrowding, housing tenure and lack of household amenities. Where possible, measures were taken at age 4 , except for lack of amenities, which was ascertained at age 2. However, if data were missing at age 4 , comparable measures at ages 11 or 15 were used. See table 1 for details of categorisation of each measure.

Indicators of SEP in earlier adulthood (ie, 26 to 53) were highest educational level attained by age 26 , 
Table 1 Indicators of socioeconomic position used in analyses.

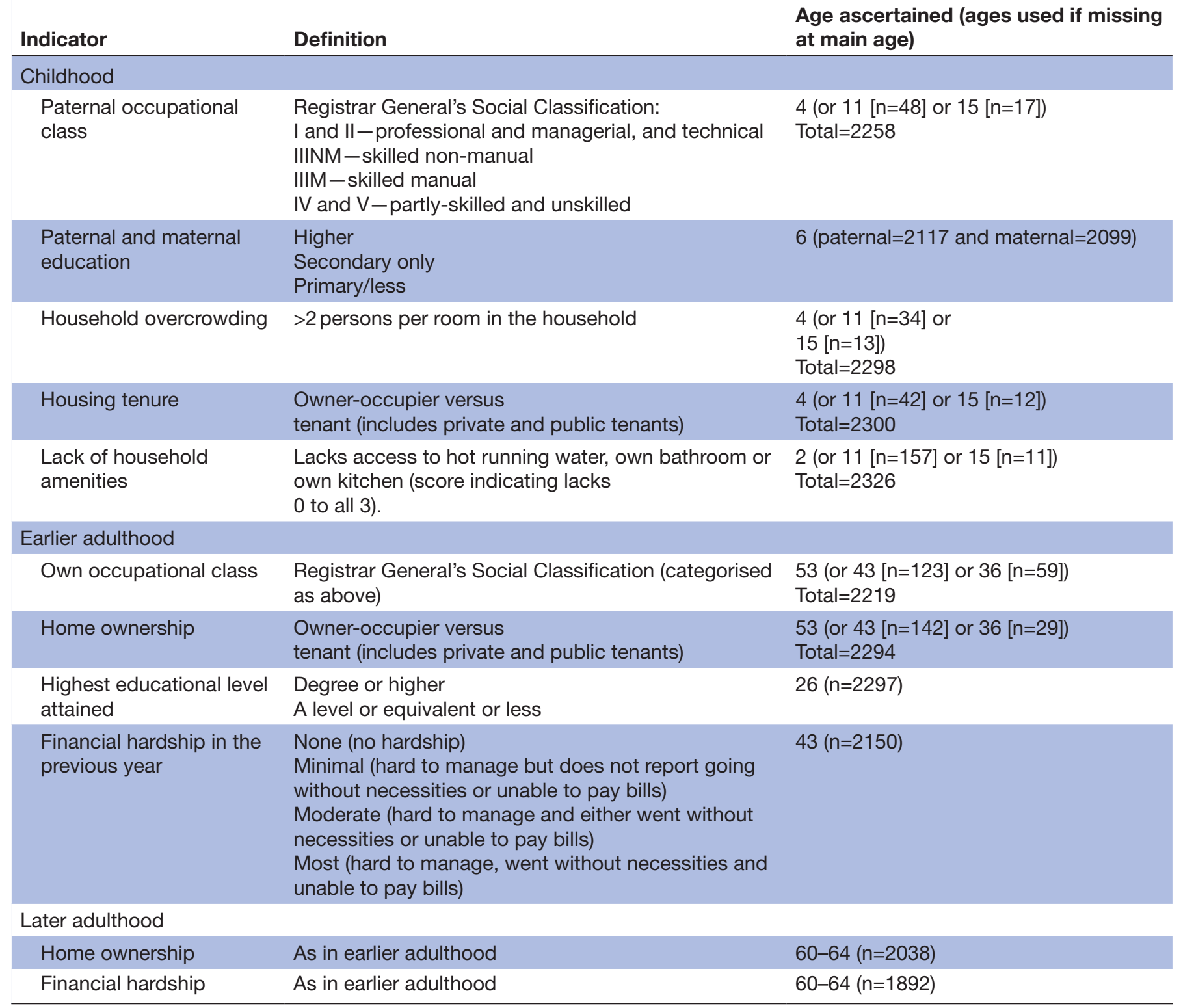

financial hardship at age 43 and own occupational class and home ownership at age 53 (or at 43 or 36 if missing at 53) (see table 1). Indicators of SEP in later adulthood (age 60-64) were home ownership and financial hardship (see table 1 ).

\section{Covariates}

Potential confounders were identified from the existing literature. ${ }^{1018}{ }^{28-31}$ Body mass index (BMI) $\left(\mathrm{kg} \mathrm{m}^{-2}\right)$ was calculated using measures of height and weight recorded by trained nurses at age 60-64. Cigarette smoking status (current, ex or never), participation in sports or vigorous leisure activities in the previous 4 weeks (inactive, 1-4 times per month, or five or more times per month) and marital status (never married, married/civil partnership, separated/divorced and widowed) were all self-reported at age 68. Participants were asked how often they consumed alcoholic drinks in the last year and to record the number of alcoholic drinks (beers, wines and spirits) they drank in the last 7 days. Units were summed to create an overall measure of alcohol consumptions in units in the previous week at age 68. Affective symptoms were measured using General Health Questionnaire-28 (GHQ$28)^{32}$ score at age $60-64$. Items were scored $0-0-1-1$ and then summed, and caseness was identified based on a cut-off of five or more. ${ }^{32}$

\section{Statistical methods}

To examine the associations of each SEP indicator with CWP, CRP and other pain at age 68, a series of multinomial logistic regression models were specified. For each SEP indicator, a crude model was first constructed and adjusted for sex. An interaction term between each SEP indicator and sex was entered and subsequent models were sex-stratified if this term was statistically significant (likelihood ratio test, $\mathrm{p}<0.05$ ). Categories of covariates 
were entered as follows: First, BMI and health behaviours (smoking, physical activity and alcohol consumption) were entered. Second, the adjustment was made for affective symptoms (GHQ-28 caseness). Finally, a fully adjusted model that included all covariates was estimated.

To ascertain whether the accumulation of low levels of SEP was associated with CWP, CRP or other pain, we derived ordinal indices that indicated, at each time point, whether the participant was in lower or higher SEP (these scores assume equal weight should be given to SEP at each life stage). We only generated these indices for indicators of SEP that had been found at any life stage to be associated with CWP, CRP or other pain and had been measured at multiple life stages. These indices were entered into regression models and adjustments were carried out in the same order as above.

Models were fit with maximum likelihood and results are presented as relative risk ratios (RRRs) with $95 \%$ CIs. Overall statistical significance of each SEP indicator in each model was assessed using the likelihood ratio test. Where covariates were missing (GHQ-28 score $[n=494$, 20.8\%]; BMI [ $\mathrm{n}=472,19.8 \%$ ]; alcohol consumption [n=243, 10.2\%]; marital status [ $\mathrm{n}=45,1.9 \%]$ and smoking status $[n=22,0.9 \%])$, these were imputed using multiple imputations with chained equations ${ }^{33}$ with 40 imputed datasets. The outcome and exposure variables were included in the imputation model but not themselves imputed. ${ }^{34}$ Parameter estimates were combined using Rubin's rules. Sensitivity analyses exploring these models with only complete cases were performed.

All data management and analysis was conducted in $\mathrm{R}^{35}$ with RStudio ${ }^{36}$ and the packages mice ${ }^{33}$ and nnet. $^{37}$

\section{RESULTS}

The characteristics of the 2378 participants included in analyses are presented in table 2 . The prevalence of CWP among women and men was $13.3 \%$ and $7.8 \%$, respectively. In women, the prevalence of CRP was $32.3 \%$ and other pain was $12.5 \%$. In men, these figures were $28.7 \%$ and $15.2 \%$, respectively. The number and proportion of individuals in the lowest SEP categories are given in table 2, with a full breakdown by sex in online supplementary tables 1-3.

There was no evidence of associations between any of the indicators of childhood SEP and CWP, CRP or other pain at age 68 (table 3; models at all stages of adjustment in supplementary table 4$)$.

Table 4 (online supplementary table 5 ) shows the RRRs of CWP, CRP and other pain (vs no pain) obtained from regression models for each indicator of SEP in earlier adulthood. There were sex differences in the associations between educational level and pain (education-sex interaction, $\mathrm{p}<0.01$ ). Women with lower levels of education were more likely to report CRP at age 68 compared with those with a degree or higher (RRR 1.93 [95\% CI: 1.01 to 3.69]) and less likely to report other pain (RRR $0.54[0.29$ to 1.00$])$. Men with lower educational levels were more likely to report CWP than men with a degree or higher (2.68 [95\% CI: 1.12 to 6.45$]$ ). Financial hardship in earlier adulthood was associated with higher risk of CWP at age 68; fully-adjusted RRR of CWP was 1.21 (95\% CI: 0.67 to 2.17 ), 2.32 (95\% CI: 1.19 to 4.52 ) and 4.44 (95\% CI: 2.02 to 9.77) for minimal, moderate and most financial hardship, respectively, compared with no financial hardship. Similar trends were observed for CRP and other pain but the RRRs were smaller and not statistically significant. In a sex-adjusted model, there was some evidence of an association between the lowest occupational classes and an increased risk of CWP (RRR 1.52 [95\% CI: 0.99 to 2.34]), which was attenuated in the fully-adjusted model (RRR 1.22 [95\% CI: 0.77 to 1.92]). Finally, being a tenant (vs being an owner-occupier) was associated with an increased risk of CWP at age 68. In a sex-adjusted model, the RRR was 1.81 (95\% CI: 1.21 to 2.72), which was slightly attenuated to 1.62 (1.06 to 2.49) after adjustment for all covariates.

Neither indicator of SEP in later adulthood (home ownership and financial hardship) was associated with pain at age 68 (table 4 and supplementary table 6 ).

As tenant status and financial hardship were the only two variables measured at multiple time points that were associated with CWP or CRP, these two were taken forward into the accumulation analyses. The number and proportion of participants in each group at the earliest and latest time points are cross-tabulated in supplementary table 7 . Online supplementary table 8 shows the number and proportion of participants at each level of the derived accumulation indices.

Results from multinomial logistic regression models examining the cumulative associations between tenant status, financial hardship and CWP, CRP and other pain are shown in table 5 (online supplementary table 9). These show that accumulation of tenant status over life was not associated with pain at age 68 . By contrast, accumulation of financial hardship across adulthood was associated with an increased risk of CWP (hardship at one point reported vs no hardship RRR 1.93 [95\% CI: 1.11 to 3.35]; hardship at both points RRR 3.90 [95\% CI: 1.20 to 12.64]).

Sensitivity analyses revealed no major differences to the models fit using imputed data (directions of associations were the same and magnitudes were similar) and are not, therefore, presented.

\section{DISCUSSION}

We aimed to investigate whether different SEP indicators at different life stages were associated with risk of reporting CWP, CRP or other pain at age 68. Experience of financial hardship and tenant status in earlier adulthood were both associated with an increased risk of CWP at age 68. Lower educational attainment was also associated with an increased risk of CWP and CRP in men and women, respectively. There was no evidence of associations between any SEP indicator in childhood 
Table 2 Characteristics of participants from the MRC National Survey of Health and Development included in analyses (sample restricted to those with data on pain at age 68 and at least one indicator of SEP [maximum $n=2378]$ ).

\begin{tabular}{|c|c|c|c|}
\hline \multicolumn{2}{|l|}{ Pain at age 68} & Women $(n=1140)$ & Men $(n=1238)$ \\
\hline \\
\hline \multicolumn{2}{|l|}{ CWP } & $164(13.3 \%)$ & $89(7.8 \%)$ \\
\hline \multicolumn{2}{|l|}{ CRP } & $400(32.3 \%)$ & $327(28.7 \%)$ \\
\hline \multicolumn{2}{|l|}{ Other pain } & $155(12.5 \%)$ & $173(15.2 \%)$ \\
\hline \multicolumn{2}{|l|}{ No pain } & $519(41.9 \%)$ & $551(48.3 \%)$ \\
\hline \multicolumn{4}{|l|}{ BMl at age $60-64, n=1906$} \\
\hline \multicolumn{2}{|l|}{ Mean (SD) $\left(\mathrm{kg} \mathrm{m}^{-2}\right)$} & $27.8(5.2)$ & $27.8(4.0)$ \\
\hline \multicolumn{4}{|l|}{ Smoking at age $68, \mathrm{n}=2356$} \\
\hline \multicolumn{2}{|l|}{ Current } & $96(7.8 \%)$ & $112(9.9 \%)$ \\
\hline \multicolumn{2}{|l|}{ Ex-smoker } & $653(53.2 \%)$ & $680(60.2 \%)$ \\
\hline \multicolumn{2}{|l|}{ Never } & $478(39.0 \%)$ & $337(29.9 \%)$ \\
\hline \multicolumn{2}{|c|}{ Alcohol units (Median [IQR]) at age $68, n=2135$} & 2.0 (0.0 to 6.0$)$ & $7.0(2.0$ to 15.0$)$ \\
\hline \multicolumn{4}{|c|}{ Leisure time physical activity at age $68, n=2352$} \\
\hline \multicolumn{2}{|c|}{ Inactive } & $733(59.7 \%)$ & $682(60.7 \%)$ \\
\hline \multicolumn{2}{|l|}{ One to four times/month } & $163(13.3 \%)$ & $120(10.6 \%)$ \\
\hline \multicolumn{2}{|c|}{ Five or more times/month } & $330(26.9 \%)$ & $324(28.7 \%)$ \\
\hline \multicolumn{4}{|c|}{ Symptoms of anxiety and depression (GHQ-28) at age $60-64, n=1884$} \\
\hline \multicolumn{2}{|c|}{ Yes $(\leq 4)$} & $222(22.4 \%)$ & $115(12.9 \%)$ \\
\hline \multicolumn{2}{|l|}{ No $(>4)$} & $768(77.6 \%)$ & $779(87.1 \%)$ \\
\hline \multicolumn{4}{|l|}{ Marital status at age $68, n=2333$} \\
\hline \multicolumn{2}{|l|}{ Single } & $39(3.2 \%)$ & $47(4.2 \%)$ \\
\hline \multicolumn{2}{|l|}{ Married } & $856(70.7 \%)$ & $912(81.2 \%)$ \\
\hline \multicolumn{2}{|l|}{ Separated/Divorced } & $167(13.8 \%)$ & $109(9.7 \%)$ \\
\hline \multicolumn{2}{|l|}{ Widowed } & $148(12.2 \%)$ & 55 (4.9\%) \\
\hline \multicolumn{4}{|l|}{ Childhood SEP (age 0-15) } \\
\hline \multicolumn{2}{|l|}{ Father's occupational class } & $291(24.8 \%)$ & $260(24.0 \%)$ \\
\hline Home ownership & Tenant status & $826(69.0 \%)$ & $773(70.1 \%)$ \\
\hline Lack of amenities & Lacks three amenities & $48(4.0 \%)$ & $47(4.2 \%)$ \\
\hline Overcrowding & Overcrowded & $67(5.6 \%)$ & $39(3.5 \%)$ \\
\hline Maternal education & Primary or less & $817(74.4 \%)$ & $742(72.8 \%)$ \\
\hline Paternal education & Primary or less & $740(67.8 \%)$ & $667(65.9 \%)$ \\
\hline Earlier adulthood SEP (age 26- & & & \\
\hline Educational level & A level or equivalent or less & $1116(93.5 \%)$ & $913(82.8 \%)$ \\
\hline Financial hardship & Most hardship & $31(2.8 \%)$ & $23(2.3 \%)$ \\
\hline Occupational class & Class IV-V & $193(17.0 \%)$ & $93(8.6 \%)$ \\
\hline Home ownership & Tenant status & $128(10.7 \%)$ & $116(10.6 \%)$ \\
\hline Later adulthood SEP (age 60/6 & & & \\
\hline Home ownership & Tenant status & $283(26.1 \%)$ & $307(32.2 \%)$ \\
\hline Financial hardship & Most hardship & $11(1.1 \%)$ & $19(2.1 \%)$ \\
\hline
\end{tabular}

For brevity, descriptive statistics for only the most adverse category of each SEP indicator are presented; a complete breakdown of the distribution of each SEP indicator by sex is given in online supplementary tables 1 and 2 . Numbers on each covariate vary due to missing data.

BMI, body mass index; CRP, chronic regional pain; CWP, chronic widespread pain; GHQ-28, General Health Questionnaire-28-item; SEP, socioeconomic position. 
Table 3 Associations between indicators of socioeconomic position in childhood and pain at age 68 .

\begin{tabular}{|c|c|c|c|c|c|c|c|}
\hline \multirow[b]{2}{*}{ Exposure } & \multirow[b]{2}{*}{$\mathbf{n}$} & \multirow[b]{2}{*}{ Model } & \multirow[b]{2}{*}{ Exposure level } & \multirow{2}{*}{$\begin{array}{l}\text { CWP versus no } \\
\text { pain } \\
\text { RRR }(95 \% \mathrm{Cl})\end{array}$} & \multirow{2}{*}{$\begin{array}{l}\text { CRP versus no } \\
\text { pain } \\
\text { RRR }(95 \% \mathrm{Cl})\end{array}$} & \multirow{2}{*}{$\begin{array}{l}\text { Other pain versus } \\
\text { no pain } \\
\text { RRR }(95 \% \mathrm{Cl})\end{array}$} & \multirow[b]{2}{*}{$P$ value } \\
\hline & & & & & & & \\
\hline \multirow{6}{*}{$\begin{array}{l}\text { Father's occupational } \\
\text { class (ref=I-II) }\end{array}$} & \multirow[t]{6}{*}{2258} & \multirow[t]{3}{*}{1} & IIINM & 1.11 (0.73 to 1.69$)$ & 0.94 (0.71 to 1.26$)$ & 0.90 (0.62 to 1.31$)$ & \multirow[t]{3}{*}{0.87} \\
\hline & & & IIIM & $1.06(0.71$ to 1.57$)$ & 1.09 (0.84 to 1.41$)$ & 0.87 (0.62 to 1.24$)$ & \\
\hline & & & IV-V & $1.29(0.87$ to 1.92$)$ & 1.00 (0.76 to 1.32$)$ & $1.00(0.70$ to 1.42$)$ & \\
\hline & & \multirow[t]{3}{*}{2} & IIINM & 1.05 (0.68 to 1.62$)$ & 0.93 (0.70 to 1.24$)$ & 0.90 (0.62 to 1.32$)$ & \multirow[t]{3}{*}{0.97} \\
\hline & & & IIIM & $0.86(0.57$ to 1.29$)$ & 1.01 (0.77 to 1.31$)$ & 0.83 (0.58 to 1.19$)$ & \\
\hline & & & IV-V & 1.05 (0.69 to 1.59$)$ & 0.93 (0.70 to 1.23 ) & 0.98 (0.68 to 1.41$)$ & \\
\hline \multirow{2}{*}{$\begin{array}{l}\text { Home ownership } \\
\text { (ref=owner occupier) }\end{array}$} & \multirow[t]{2}{*}{2300} & 1 & Tenant & $1.06(0.78$ to 1.43$)$ & 1.05 (0.85 to 1.29$)$ & $1.02(0.77$ to 1.34$)$ & 0.96 \\
\hline & & 2 & Tenant & 0.88 (0.64 to 1.21$)$ & 0.97 (0.78 to 1.20$)$ & 0.98 (0.74 to 1.30$)$ & 0.88 \\
\hline \multirow{2}{*}{$\begin{array}{l}\text { Lack of amenities } \\
\text { (ref=lacks } 0 \text { ) }\end{array}$} & \multirow[t]{2}{*}{2326} & 1 & Lacks one or more & $1.21(0.92$ to 1.60$)$ & 1.03 (0.85 to 1.24$)$ & 0.99 (0.77 to 1.27$)$ & 0.57 \\
\hline & & 2 & Lacks one or more & 1.14 (0.85 to 1.52$)$ & 1.01 (0.83 to 1.22$)$ & 0.98 (0.76 to 1.26$)$ & 0.81 \\
\hline \multirow{2}{*}{$\begin{array}{l}\text { Overcrowding } \\
\text { (ref=not overcrowded) }\end{array}$} & \multirow[t]{2}{*}{2298} & 1 & Overcrowded & 1.12 (0.59 to 2.11$)$ & 1.17 (0.75 to 1.82$)$ & 0.72 (0.36 to 1.44$)$ & 0.56 \\
\hline & & 2 & Overcrowded & $1.01(0.52$ to 1.95$)$ & $1.13(0.72$ to 1.77$)$ & 0.71 (0.35 to 1.44$)$ & 0.64 \\
\hline \multirow{4}{*}{$\begin{array}{l}\text { Maternal education } \\
\text { (ref=diploma/degree) }\end{array}$} & \multirow[t]{4}{*}{2117} & \multirow[t]{2}{*}{1} & Secondary & 1.06 (0.58 to 1.95$)$ & 0.76 (0.51 to 1.13$)$ & 0.56 (0.34 to 0.95$)$ & \multirow[t]{2}{*}{0.40} \\
\hline & & & Primary & $1.08(0.65$ to 1.82$)$ & $0.82(0.59$ to 1.13$)$ & 0.75 (0.49 to 1.13$)$ & \\
\hline & & \multirow[t]{2}{*}{2} & Secondary & 1.01 (0.54 to 1.88$)$ & $0.74(0.50$ to 1.11$)$ & 0.57 (0.34 to 0.97$)$ & \multirow[t]{2}{*}{0.38} \\
\hline & & & Primary & 0.94 (0.55 to 1.61$)$ & 0.76 (0.54 to 1.06$)$ & 0.73 (0.48 to 1.11$)$ & \\
\hline \multirow{4}{*}{$\begin{array}{l}\text { Paternal education } \\
\text { (ref=diploma/degree) }\end{array}$} & \multirow[t]{4}{*}{2099} & \multirow[t]{2}{*}{1} & Secondary & $1.12(0.66$ to 1.87$)$ & 1.26 (0.89 to 1.78$)$ & 0.83 (0.53 to 1.30$)$ & \multirow[t]{2}{*}{0.68} \\
\hline & & & Primary & $1.11(0.73$ to 1.67$)$ & 1.07 (0.81 to 1.42$)$ & $0.84(0.60$ to 1.20$)$ & \\
\hline & & \multirow[t]{2}{*}{2} & Secondary & 0.99 (0.58 to 1.69$)$ & $1.19(0.84$ to 1.70$)$ & $0.80(0.51$ to 1.27$)$ & \multirow[t]{2}{*}{0.64} \\
\hline & & & Primary & $0.90(0.58$ to 1.39$)$ & $0.97(0.72$ to 1.30$)$ & 0.81 (0.57 to 1.16$)$ & \\
\hline
\end{tabular}

Model 1: sex-adjusted and Model 2: adjusted for sex, BMI, smoking, alcohol, leisure-time physical activity, GHQ-28 caseness and marital status.

CRP, chronic regional pain; CWP, chronic widespread pain.

or later adulthood and any pain outcome at age 68 . Our second aim was to assess whether observed associations were cumulative across different life stages and we found that there was a cumulative association between financial hardship during earlier and later adulthood and increased risk of CWP at age 68.

Our finding of stronger and more consistent associations between indicators of SEP in earlier adulthood and pain than with indicators of SEP in childhood or later adulthood, suggests that earlier adulthood may be a sensitive period. Financial hardship appears to be particularly important. This variable captures both subjective and objective elements of hardship (ie, feeling unable to manage or being unable to pay bills, or both). There may, therefore, be a combination of psychosocial and material elements that are associated with an increased risk of CWP. It is also especially interesting that financial hardship in later adulthood was not independently associated with CWP but when combined with the same variable in earlier adulthood, a clear inverse association was observed. This suggests that, despite the lack of strong evidence of an association between financial hardship in later adulthood and CWP at 68, intervening to reduce the burden of hardship in later as well as earlier adulthood may prove beneficial in reducing the prevalence of CWP in older age.

The interaction between education and sex also requires explanation. An increased risk of CWP or CRP with lower levels of education is in line with our initial hypotheses but it is not clear why lower education was associated with an increased risk of CWP among men but with an increased risk of CRP among women. The results may be partly explained by the fact that the binary categorisation of education used in our analyses captured more of the relevant variability in educational attainment among men than women; in our sample, $6.5 \%$ of women had a degree or higher compared with $17.2 \%$ of men (see online supplementary table 2). In addition, it may be the case that among this generation, comparing those who have a degree or higher with those with a lower level of educational attainment provides a more appropriate level of differentiation between higher and lower SEP among men than women. Previous work using the NSHD has shown that the normative work-family life course patterns for women was one of forming families earlier in life when compared with men. ${ }^{38} 39$ Therefore, among this generation, achieving a university degree may have been less likely to have provided women than men with access 


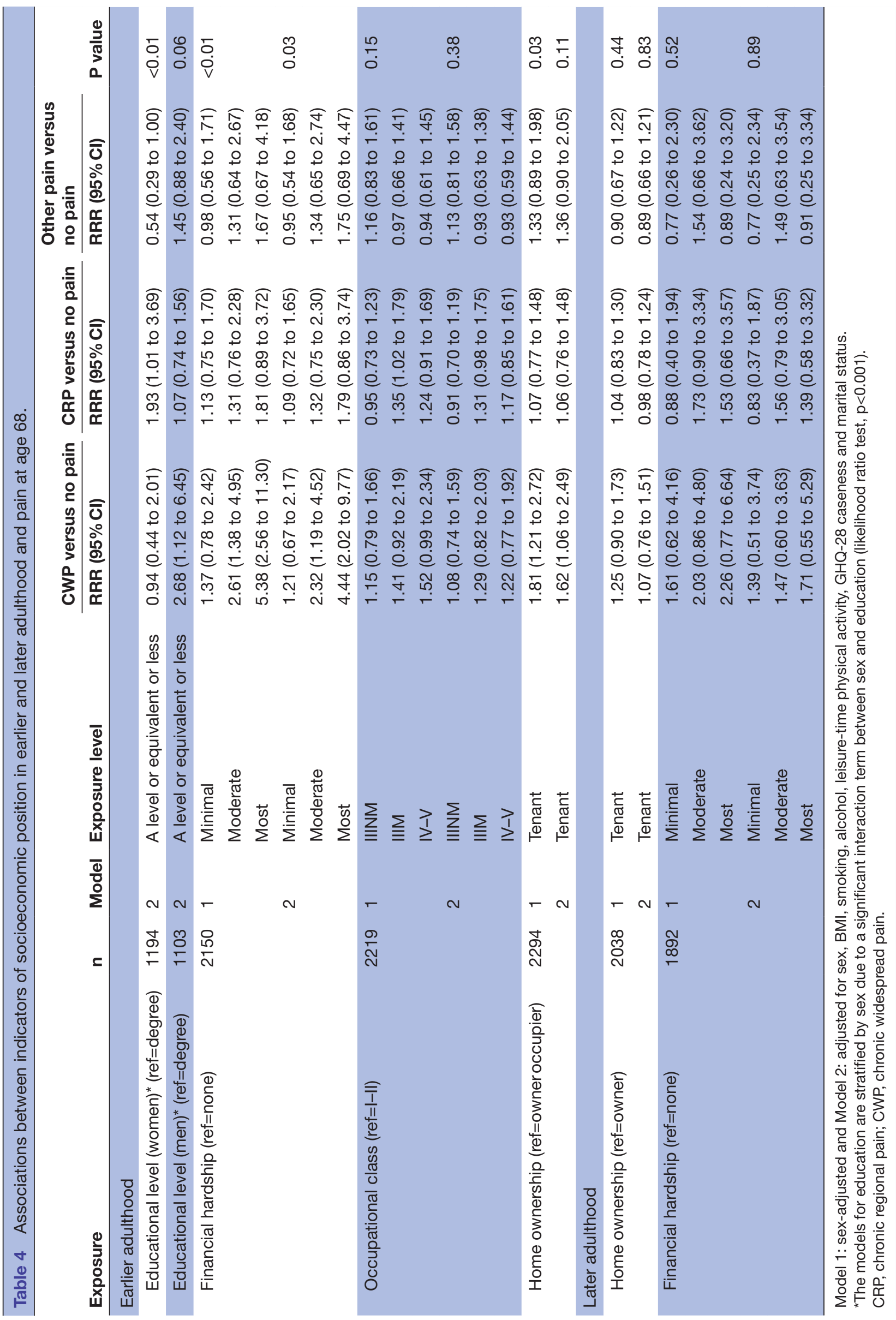




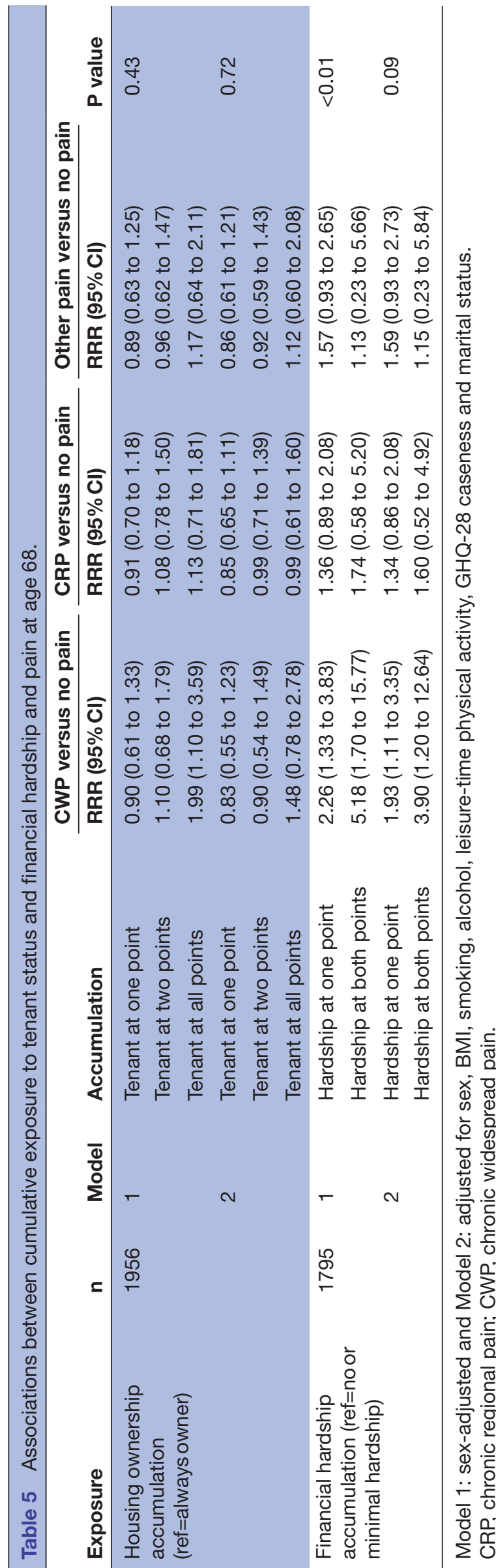

to resources (such as better remunerated work) associated with a lower risk of CWP.

Although we found evidence that earlier adulthood may be a sensitive period, it is also clear that the choice of indicator is important as there was limited evidence of an association between occupational class and CWP or CRP. This is surprising given previous findings from the 1958 British birth cohort. ${ }^{19} 19$ These previous analyses showed that lower parental occupational class in childhood and own occupational class at age 42 were associated with an increased risk of CWP at age 45 and that the association between own occupational class at 42 and CWP persisted after adjustment for parental occupational class in childhood (and in the case of Macfarlane $e t$ al ${ }^{18}$ adjustment for potential confounders/mediators). Reasons for the discrepancy with our findings may be attributable to differences in study design, particularly the ages at which pain was measured. Additionally, due to social, political and cultural changes over the course of the 20th century, conditions at the time of birth in each of the cohorts were different. For example, participants in the NSHD were born in 1946, which was the period immediately after World War II when food rationing was still in effect and important changes in housing regulations had not yet been passed, and so will have experienced poorer absolute economic and environmental conditions in early life than the cohort born in 1958. Further, the effects of occupation may act only contemporaneously in the aetiology of CWP, through the immediate psychosocial or physical demands of the work, for example. ${ }^{16174041}$

Goosby ${ }^{20}$ found that childhood conditions (ie, self-reported parental education, receipt of financial assistance and having gone hungry) were associated with chronic pain prevalence in adulthood (ages 25-64). Differences between this study's findings and our own could be attributable to differences in the indicators of childhood socioeconomic circumstances used. In addition, the associations for childhood SEP indicators observed by Goosby ${ }^{20}$ were somewhat attenuated in models that included adulthood SEP (income, education and benefit receipt since age 18). The latter were all associated with chronic pain in the expected directions. The fact that receipt of benefits was associated with chronic pain in Goosby's study ${ }^{20}$ is consistent with our finding that financial hardship was associated with CWP.

This study has a number of strengths. The NSHD is largely representative of the population of older adults in Great Britain despite some losses to follow-up, ${ }^{24}{ }^{26}$ meaning that results are likely to be generalisable to this generation. We examined a wide range of SEP indicators with data being collected over a 60 -year-period. The study is subject to very limited (if any) recall bias as data were collected prospectively. There is also, therefore, limited risk of exposure or outcome misclassification (ie, participants being incorrectly labelled as lower or higher SEP).

Some limitations are also noted. It was not possible to examine incident pain as no data on CWP or CRP had been ascertained before age 68 . As the onset of CWP and 
CRP may occur earlier in life and persist into later adulthood, future work will need to establish the temporality of associations. Although we adjusted for a range of covariates, we only did so at one time point. Changes in these variables may be associated with changes in pain state over time and failing to account for their time-varying nature might have resulted in residual confounding. There might also be survivor bias as lower SEP in childhood was associated with lower survival rates into adulthood in NSHD. ${ }^{42}$ If so, this would bias associations towards the null and could partially explain why there was no association between childhood SEP and CWP or CRP at age 68 . Finally, results might not be generalizable to younger, more ethnically diverse cohorts so the study should be replicated with subsequent generations, particularly the 1958 British birth cohort as participants in that study age, which also contains data on SEP and pain.

These results have important implications for public policy. Given its high prevalence, cost and associated disability, prevention of CWP and CRP should be considered a key public health priority. Policymakers should ensure that socioeconomic adversity across life is addressed in public health interventions, particularly the role that housing, education and financial hardship may play.

Acknowledgements The authors are grateful to NSHD study members for their continuing participation in the study. We also thank members of the NSHD scientific and data collection teams.

Contributors MAJ had full access to the data and takes full responsibility for the integrity and accuracy of the analysis. MAJ, SGM and RB conceived the idea for this study. MAJ, SGM, RB and RC contributed to study design. MAJ analysed the data and drafted the manuscript. All authors contributed critically to the manuscript and provided final approval of the version to be published.

Funding This work was supported by the UK MRC that provides core funding for the MRC NSHD and supported SGM and RC (programme code: MC_UU_12019/4). SGM was also supported by MRC grant MR/L010399/1. MAJ was supported while carrying out this work by a grant from Great Ormond Street Hospital for Children NHS Foundation Trust. RB was supported in part by grant MR/R016372/1 for the King's College London MRC Skills Development Fellowship programme funded by the UK Medical Research Council and grant IS-BRC-1215-20018 for the National Institute for Health Research (NIHR) Biomedical Research Centre at South London and Maudsley NHS Foundation Trust and King's College London.

Disclaimer The views expressed are those of the authors and not necessarily those of the MRC, NHS, NIHR or the Department of Health and Social Care. The funders of the study had no role in the study design, data collection, data analysis, data interpretation, writing of the report or decision to submit the article for publication.

\section{Competing interests None declared.}

Patient consent for publication Not required.

Ethics approval Ethical approval was received for each data collection; in 20142015, this was obtained from the Queen Square Ethics Committee (14/L0/1073) and the Scotland A Research Ethics Committee (14/SS/1009) and written informed consent was obtained from study members.

Provenance and peer review Not commissioned; externally peer reviewed.

Data sharing statement Data used in this publication are available to bona fide researchers upon request to the NSHD Data Sharing Committee via a standard application procedure. Further details can be found at http://www.nshd.mrc.ac.uk/ data and doi: 10.5522/NSHD/Q101; 10.5522/NSHD/Q102 and 10.5522/NSHD/Q103.

Open access This is an open access article distributed in accordance with the Creative Commons Attribution 4.0 Unported (CC BY 4.0) license, which permits others to copy, redistribute, remix, transform and build upon this work for any purpose, provided the original work is properly cited, a link to the licence is given, and indication of whether changes were made. See: https://creativecommons.org/ licenses/by/4.0/.

\section{REFERENCES}

1. Rice AS, Smith BH, Blyth FM. Pain and the global burden of disease. Pain 2016;157:791-6.

2. Thomas E. Pain in older people. In: Croft P, Blyth FM, van Der Windt D, eds. Chronic Pain Epidemiology: From Aetiology to Public Health. Oxford: Oxford University Press, 2010:185-99.

3. Wolfe F, Smythe HA, Yunus MB, et al. The American College of Rheumatology 1990 Criteria for the Classification of Fibromyalgia. Report of the Multicenter Criteria Committee. Arthritis Rheum 1990;33:160-72.

4. Fayaz A, Croft P, Langford RM, et al. Prevalence of chronic pain in the UK: a systematic review and meta-analysis of population studies. BMJ Open 2016;6:e010364.

5. Mansfield KE, Sim J, Jordan JL, et al. A systematic review and metaanalysis of the prevalence of chronic widespread pain in the general population. Pain 2016;157:55-64.

6. Andrews P, Steultjens M, Riskowski J. Chronic widespread pain prevalence in the general population: a systematic review. Eur J Pain 2018;22:5-18.

7. Blyth FM, March LM, Brnabic AJM, et al. Chronic pain in Australia: a prevalence study. Pain 2001;89(2):127-34.

8. Gatchel RJ, Peng YB, Peters ML, et al. The biopsychosocial approach to chronic pain: scientific advances and future directions. Psychol Bull 2007;133:581-624.

9. Blyth FM, March LM, Brnabic AJ, et al. Chronic pain in Australia: a prevalence study. Pain 2001;89(2-3):127-34.

10. Bridges S. Chapter 9 Chronic Pain. In: Craig R, Mindell J, eds. Health Survey for England 2011. Leeds: Health and Social Care Information Centre, 2011.

11. Elliott AM, Smith BH, Penny KI, et al. The epidemiology of chronic pain in the community. Lancet 1999;354:1248-52.

12. Hagen $\mathrm{K}, \mathrm{Zwart} \mathrm{JA}$, Svebak S, et al. Low socioeconomic status is associated with chronic musculoskeletal complaints among 46,901 adults in Norway. Scand J Public Health 2005;33:268-75.

13. Raftery MN, Sarma K, Murphy AW, et al. Chronic pain in the Republic of Ireland-community prevalence, psychosocial profile and predictors of pain-related disability: results from the Prevalence, Impact and Cost of Chronic Pain (PRIME) study, part 1. Pain 2011;152:1096-103.

14. Toblin RL, Mack KA, Perveen G, et al. A population-based survey of chronic pain and its treatment with prescription drugs. Pain 2011;152:1249-55.

15. Galobardes B, Lynch J, Smith GD. Measuring socioeconomic position in health research. Br Med Bull 2007;81-82:21-37.

16. Galobardes B, Shaw M, Lawlor DA, et al. Indicators of socioeconomic position (part 1). J Epidemiol Community Health 2006;60:7-12.

17. Galobardes B, Shaw M, Lawlor DA, et al. Indicators of socioeconomic position (part 2). J Epidemiol Community Health 2006;60:95-101.

18. Macfarlane GJ, Norrie G, Atherton K, et al. The influence of socioeconomic status on the reporting of regional and widespread musculoskeletal pain: results from the 1958 British Birth Cohort Study. Ann Rheum Dis 2009;68:1591-5.

19. Power C, Atherton K, Strachan DP, et al. Life-course influences on health in British adults: effects of socio-economic position in childhood and adulthood. Int J Epidemiol 2007;36:532-9.

20. Goosby BJ. Early life course pathways of adult depression and chronic pain. J Health Soc Behav 2013;54:75-91.

21. Ben-Shlomo Y, Kuh D. A life course approach to chronic disease epidemiology: conceptual models, empirical challenges and interdisciplinary perspectives. Int J Epidemiol 2002;31:285-93.

22. Wadsworth M, Kuh D, Richards M, et al. Cohort Profile: The 1946 National Birth Cohort (MRC National Survey of Health and Development). Int J Epidemiol 2006;35:49-54.

23. Wadsworth ME, Butterworth SL, Hardy RJ, et al. The life course prospective design: an example of benefits and problems associated with study longevity. Soc Sci Med 2003;57:2193-205.

24. Stafford M, Black S, Shah I, et al. Using a birth cohort to study ageing: representativeness and response rates in the National Survey of Health and Development. Eur J Ageing 2013;10:145-57.

25. Kuh D, Pierce M, Adams J, et al. Cohort profile: updating the cohort profile for the MRC National Survey of Health and Development: a 
new clinic-based data collection for ageing research. Int $J$ Epidemiol 2011;40:e1-9.

26. Kuh D, Wong A, Shah I, et al. The MRC National Survey of Health and Development reaches age 70: maintaining participation at older ages in a birth cohort study. Eur J Epidemiol 2016;31:1135-47.

27. Muthuri SG, Kuh D, Bendayan R, et al. Chronic physical illness in early life and risk of chronic widespread and regional pain at age 68: evidence from the 1946 British birth cohort. Pain 2016;157:2382-9.

28. Heim N, Snijder MB, Deeg DJ, et al. Obesity in older adults is associated with an increased prevalence and incidence of pain. Obesity 2008;16:2510-7.

29. Mundal I, Gråwe RW, Bjørngaard JH, et al. Prevalence and longterm predictors of persistent chronic widespread pain in the general population in an 11-year prospective study: the HUNT study. BMC Musculoskelet Disord 2014;15:213.

30. Hartvigsen J, Christensen K. Active lifestyle protects against incident low back pain in seniors: a population-based 2-year prospective study of 1387 Danish twins aged $70-100$ years. Spine 2007;32:76-81.

31. Elliott AM, Smith BH, Hannaford PC, et al. The course of chronic pain in the community: results of a 4-year follow-up study. Pain 2002;99(1-2):299-307.

32. Goldberg DP, Hillier VF. A scaled version of the General Health Questionnaire. Psychol Med 1979;9:139-45.
33. Buuren S, Groothuis-Oudshoorn K. mice: Multivariate Imputation by Chained Equations in R. J Stat Softw 2011;45:67.

34. Sterne JA, White IR, Carlin JB, et al. Multiple imputation for missing data in epidemiological and clinical research: potential and pitfalls. BMJ 2009;338:b2393.

35. R: A language and environment for statistical computing [program]. Vienna, Austria: R Foundation for Statistical Computing, 2015.

36. RStudio: Integrated Development for R [program]. Boston, MA, USA: RStudio, Inc, 2015

37. Venables WN, Ripley BD. Modern Applied Statistics with S. New York: Springer, 2002.

38. McMunn A, Lacey R, Worts D, et al. De-standardization and gender convergence in work-family life courses in Great Britain: a multichannel sequence analysis. Adv Life Course Res 2015;26:60-75.

39. Stafford M, Lacey R, Murray E, et al. Work-family life course patterns and work participation in later life. Eur J Ageing 2018;29.

40. Woods V. Work-related musculoskeletal health and social support. Occup Med 2005;55:177-89.

41. Christensen JO, Knardahl S. Work and neck pain: a prospective study of psychological, social, and mechanical risk factors. Pain 2010;151:162-73.

42. Kuh D, Hardy R, Langenberg $C$, et al. Mortality in adults aged 26-54 years related to socioeconomic conditions in childhood and adulthood: post war birth cohort study. BMJ 2002;325:1076-80. 